\title{
IMOBILIZAÇÃO E ESTABILIZAÇÃO DE XILANASE RECOMBINANTE DE Bacillus subtilis EM QUITOSANA-GLIOXIL
}

\author{
T. S. S. MILESSI ${ }^{1}$, W. KOPP ${ }^{1}$, A. B. NETO ${ }^{2}$, P. W. TARDIOLI ${ }^{1}$ e R. L. C. GIORDANO ${ }^{1}$ \\ ${ }^{1}$ Universidade Federal de São Carlos, Departamento de Engenharia Química \\ ${ }^{2}$ VERDARTIS, Desenvolvimento Biotecnológico \\ E-mail para contato: thais.milessi@gmail.com
}

\begin{abstract}
RESUMO - O aproveitamento da fração hemicelulósica da biomassa é essencial para a viabilidade da utilização de materiais lignocelulósicos em bioprocessos. As xilanases hidrolisam ligações glicosídicas entre unidades de xilose da hemicelulose, podendo ser aplicadas na etapa de pré-tratamento para liberação de açúcares fermentescíveis. A imobilização de xilanase é uma alternativa interessante, pois pode reduzir o custo da etapa de pré-tratamento. A quitosana-glioxil é um suporte de imobilização promissor devido ao seu baixo custo e por permitir a imobilização de enzimas por interações covalentes multipontuais. Neste contexto, o presente trabalho utilizou quitosana-glioxil para imobilizar endoxilanase recombinante de B. subtilis expressa em E. coli DH5a. A imobilização foi realizada à $\mathrm{pH} 10.0$ e $25^{\circ} \mathrm{C}$. O rendimento de imobilização foi de $76 \%$ com uma atividade recuperada de 53.6\%. A enzima imobilizada apresentou meia vida de 5.9 h à $56^{\circ} \mathrm{C}$ e pH 5.5, sendo 75x mais estável que a enzima solúvel.
\end{abstract}

\section{INTRODUÇÃO}

Os materiais lignocelulósicos vêm ganhando destaque como matéria prima em bioprocessos devido à sua grande disponibilidade, baixo custo e por não competir com a produção de alimentos (Nigam; Singh, 2011). Seu potencial como fonte de carbono sustentável está diretamente relacionado com sua composição, uma vez que são compostos principalmente por 40-50\% de celulose, 20-25\% de hemicelulose e 20-30\% de lignina, dependendo do material (Fengel; Wegener, 1983).

A hemicelulose é um heteropolissacarídeo constituído principalmente de xilose (Carvalho et al., 2013). A partir de uma etapa de pré-tratamento, termoquímico ou enzimático, a matriz fibrosa da biomassa pode ser rompida e os açúcares fermentescíveis liberados (Mosier et al., 2005). Entretanto, esta etapa acarreta custos adicionais significativos ao processo e ainda está em fase de pesquisa e implantação em escala industrial (Mussato et al., 2010).

As xilanases ( $\beta$-1,4-D-xilanase) são enzimas que catalisam a hidrólise das ligações glicosídicas entre as unidades de xilose da fração hemicelulósica, podendo ser divididas em dois grandes grupos: as endoxilanases e as $\beta$-D-xilosidases (Carvalho et al., 2013). As endoxilanases hidrolisam aleatoriamente a cadeia principal do polímero de hemicelulose, enquanto as $\beta$-D-xilosidases agem na extremidade não redutora da cadeia, liberando xilose (Manrich, 2012). Estas enzimas são produzidas, 
em sua forma nativa, por diferentes microrganismos (fungos filamentosos, leveduras e bactérias) entre eles podemos citar os gêneros Aspergillus, Trichoderma, Fibrobacter, Clostridium e Bacillus (Carvalho et al., 2013).

As xilanases são extensivamente utilizadas nas indústrias de papel e alimentos; devido à sua capacidade catalítica estas enzimas xilanolíticas apresentam também grande potencial para aplicação na bioconversão de lignocelulósicos em açúcares fermentescíveis (Carvalho et al., 2013). Entretanto, a utilização de xilanases na degradação de materiais lignocelulósicos é limitadada por sua instabilidade em determinadas condições de processo e principalmente por seu alto custo de obtenção.

A xilanase de $B$. subtilis possui $\mathrm{pH}$ e temperaturas ótimos próximos a 5.0 e $50^{\circ} \mathrm{C}$, respectivamente, e apresentam maior concentração de aminoácidos básicos do que xilanases de fungos (Bernier et al., 1983). A xilanase utilizada neste trabalho apresenta predominantemente atividade de endoxilanase e foi expressa em E. coli DH5 $\alpha$.

A condução do processo de hidrólise à elevadas temperaturas pode evitar a contaminação do meio extremamente rico em monossacarídeos e aumentar a velocidade da reação (Aragon et al., 2013). Porém, Rojas et al. (2013) observaram que a endoxilanase recombinante de Bacillus subtilis apresentou um tempo de meia-vida de apenas 2,7 minutos à $60^{\circ} \mathrm{C}$. Desta maneira, uma estratégia para contornar esta instabilidade frente às condições de processo é a utilização da enzima imobilizada o que também permitiria a recuperação e reutilização do biocatalisador diminuindo consideravelmente o custo global do processo.

A imobilização de enzimas confere diversas vantagens ao biocatalisador, como a facilidade de separação e recuperação do produto e maior estabilidade térmica e frente ao pH. A imobilização covalente multipontual de enzimas em suportes ativados com grupos glioxil pode ainda aumentar a estabilidade do derivado enzimático uma vez que diminui a ocorrência de distorções tridimensionais na estrutura da proteína (Lopez et al., 2005). Além disso, a facilidade de separação do sistema imobilizado do meio permite sua reutilização, resultando na redução do custo da etapa de hidrólise da hemicelulose (Sheldon, 2007).

A quitosana é um biopolímero obtido a partir da desacetilação da quitina de fungos ou crustáceos que apresenta grande potencial como suporte para a imobilização de enzimas por ser um polissacarídeo abundante e barato (Silva et al., 2012). A quitosana é biocompatível, biodegradável e possui uma elevada densidade de grupos amina primária que podem ser modificados quimicamente formando grupos glioxil extremamente reativos (Kumar, 2000).

Neste contexto, o presente trabalho teve como objetivo a obtenção de um derivado de xilanase recombinante de Bacillus subtilis (BsXA) imobilizado em gel de quitosana-glioxil visando sua estabilização térmica. 


\section{9 a 22 de outubro de 2014 \\ Florianópolis/SC}

\section{MATERIAIS E MÉTODOS}

\subsection{Materiais}

Xilanase recombinante de Bacillus subtilis (BsXA) produzida pela Verdartis (Brasil), quitosana com $85 \%$ de desacetilação adquirida da Polymar S. A. (Ceará, Brasil), borohidreto de sódio e xilana de bétula adquiridas da Sigma-Aldrich SA (St. Louis, MO, EUA). Outros reagentes de grau analítico também foram utilizados.

\subsection{Métodos}

Preparo da Quitosana: O gel de quitosana foi preparado de acordo com metodologia de Silva (2013). Quitosana em pó $4 \%(\mathrm{~m} / \mathrm{m})$ foi solubilizada em ácido acético $2 \%(\mathrm{v} / \mathrm{v})$ e homogeneizada por 30 minutos à temperatura ambiente. A solução homogênea foi então aquecida e mantida a $50{ }^{\circ} \mathrm{C}$. $\mathrm{KOH} 0.5 \mathrm{M}$ foi adicionado na proporção 3:2 (v/v) (volume de KOH/volume de solução) e a solução foi mantida sob agitação por 1 hora.

Ativação Suporte Quitosana-Glioxil: Quitosana ativada com grupos glioxil foi preparada por uma nova metodologia. Primeiramente, grupos epóxidos foram introduzidos na superfície do suporte pela reação de $10 \mathrm{~g}$ do gel de quitosana com o reagente epicloridrina em meio alcalino e na presença de acetona $(4.4 \mathrm{~mL}$ de NaOH $20 \mathrm{M}, 1.6 \mathrm{~mL}$ de acetona e $1.1 \mathrm{~mL}$ de epicloridrina). A reação foi mantida sob agitação mecânica constante por 16 horas em temperatura ambiente. Em seguida, os grupos epóxidos introduzidos na superfície do suporte foram hidrolisados à grupos gliceril através da incubação do suporte em ácido sulfúrico 0.5 M durante uma hora. Ao final, os grupos gliceril foram oxidados à grupos glioxil empregando uma solução de periodato de sódio $0.1 \mathrm{M}$ na proporção de 2 $\mathrm{mL}$ de periodato/g de gel. Entre cada etapa da ativação o suporte foi filtrado e exaustivamente lavado com agua destilada.

Determinação de Proteínas Totais: A quantificação da concentração de proteínas dos extratos enzimáticos foi determinada pelo método de Bradford (1976).

Determinação da Atividade Enzimática de BsXA: A atividade de xilanase foi medida de acordo com metodologia utilizada por Manrich (2012) na qual a liberação de açúcares redutores ao longo do processo de hidrólise de xilana de bétula $(1 \% \mathrm{~m} / \mathrm{v})$, catalisada pela enzima, foi quantificada. $\mathrm{O}$ substrato foi constituído de xilana de bétula em tampão citrato $50 \mathrm{mM} \mathrm{pH} \mathrm{5.5.} \mathrm{Enzima} \mathrm{livre} \mathrm{ou}$ imobilizada foram adicionadas ao substrato e incubadas a $50{ }^{\circ} \mathrm{C}$ por $10 \mathrm{~min}$. Alíquotas foram retiradas em intervalos de 2 minutos e os açúcares redutores liberados foram quantificados pelo método do ácido dinitrosalicílico (DNS) (Miller, 1959). Uma unidade de atividade (UI) foi considerada como a quantidade de enzima necessária para liberar $1 \mu \mathrm{mol}$ de xilose por minuto nas condições de ensaio.

Imobilização de BsXA: Os procedimentos de imobilização foram realizados à baixa carga de proteína visando evitar problemas com limitação de transferência de massa intrapartícula. Quitosanaglioxil foi suspensa na solução enzimática $(0.25 \mathrm{mg} / \mathrm{mL}$ e $11.48 \mathrm{UI} / \mathrm{mL})$ na proporção $1: 10$ Vgel/Vsolução em tampão bicarbonato de sódio (100 mM e pH 10.0). A suspensão foi mantida à 25 
${ }^{\circ} \mathrm{C}$ sob agitação constante, amostras foram retiradas em intervalos periódicos e a atividade enzimática e concentração de proteínas totais foram medidas. Ao final do processo as bases de Schiff formadas e os grupos aldeído remanescentes no suporte foram reduzidos com borohidreto de sódio $(1 \mathrm{mg} / \mathrm{mL}, 4$ ${ }^{\circ} \mathrm{C}, 30 \mathrm{~min}$ ). Posteriormente, o derivado foi exaustivamente lavado com tampão citrato $50 \mathrm{mM} \mathrm{pH} 4.8$ e seco por sucção à vácuo.

Estabilidade Térmica da BsXA: A estabilidade térmica das enzimas livre e imobilizada foi realizada à $56{ }^{\circ} \mathrm{C}$, incubando-se as enzimas em tampão citrato $50 \mathrm{mM} \mathrm{pH} \mathrm{5.5.} \mathrm{Durante} \mathrm{o} \mathrm{ensaio,}$ alíquotas da solução de enzima livre ou uma massa conhecida da enzima imobilizada foram coletadas para quantificação da atividade residual e estimativa do tempo de meia-vida.

\section{RESULTADOS}

A quitosana é um material abundante e de baixo custo utilizado em estudos para imobilização de diversas enzimas (Silva et al., 2012; Mendes et al, 2011; Kumar, 2000). Além de suas características vantajosas e de seu baixo custo, sua utilização pode ainda significar uma alternativa interessante para o aproveitamento dos resíduos das industrias de frutos do mar (Rodrigues et al., 2008). Sua aplicação como suporte para a imobilização de enzimas através da ativação com grupos glioxil utilizando epicloridrina como agente ativador é um método novo e promissor, uma vez que a epicloridrina permite a ativação e o entrecruzamento do suporte em uma única etapa.

Xilanase recombinante de Bacillus subtilis foi imobilizada em gel de quitosana-glioxil visando obtenção de um derivado de elevada atividade e estabilidade. $\mathrm{O}$ acompanhamento do ensaio de imobilização pode ser observado na Figura 1. Não foi possível acompanhar a atividade na suspensão devido a baixa dispersibilidade das partículas de quitosana em $\mathrm{pH}$ 10.0, ocasionada pela forte interação iônica do polímero em valores de $\mathrm{pH}$ alcalinos.

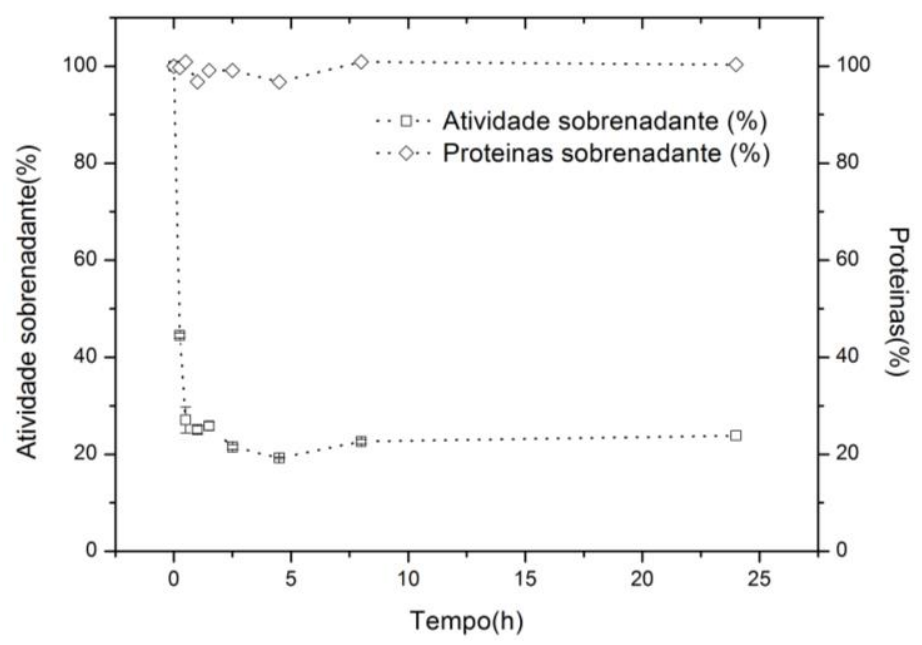

Figura 1 - Cinética de imobilização da xilanase recombinante de Bacillus subtilis (BsXA) em quitosana-glioxil. 


\section{9 a 22 de outubro de 2014 \\ Florianópolis/SC}

O processo de imobilização aconteceu rapidamente, com 30 minutos de processo apenas $27.08 \%$ da atividade inicial oferecida foi observada no sobrenadante. A rápida cinética de imobilização observada se deve, provavelmente, à elevada concentração de grupos glioxil na superfície do suporte. A imobilização por ligações covalentes multipontuais em suportes ativados com grupos glioxil ocorre em duas etapas, primeiramente ligações unipontuais são formadas entre a enzima e o suporte (bases de shiff), estas ligações são reversíveis de forma que a enzima alterna entre a forma livre e imobilizada obedecendo um equilíbrio químico. Em uma segunda etapa duas ou mais bases de shiff são formadas ao mesmo tempo entre a enzima e o suporte evitando assim a dessorção da enzima. A encubação do sistema enzima-suporte por tempos maiores favorece a formação de um maior número de ligações covalentes entre a enzima e o suporte, sendo o que caracteriza a técnica de imobilização multipontual. Geralmente quanto maior o número de uniões covalentes entre a enzima e o suporte maior será o incremento observado na estabilidade térmica e operacional da enzima (Guisan, 1988).

Assim sendo, considerando o mecanismo de imobilização multipontual, o ensaio foi estendido até 24 horas uma vez que a enzima solúvel mostrou-se estável por todo o tempo de processo nas condições de estudo. Tal estratégia foi aplicada visando aumentar a estabilidade e garantir uma boa imobilização enzimática, uma vez que de acordo com Lopez et al. (2005), quanto maior o tempo de imobilização, maior a concentração de ligações multipontuais formadas, garantindo assim uma maior estabilidade. De fato, Rodrigues et al. (2008) estudando a imobilização de lipase de Candida antarctica em suportes quitosana e agarose, observaram que derivados mais estáveis foram obtidos utilizando-se tempos de imobilização mais longos devido ao aumento no número de ligações covalentes multipontuais enzima-suporte.

Após 24 horas de imobilização ainda se observava $23.85 \%$ de atividade no sobrenadante, indicando que os grupos glioxil disponíveis no suporte provavelmente estavam saturados. Esta atividade residual pode-se ainda ser atribuída a presença de proteínas contaminantes no derivado, as quais podem ocupar sítios de ligação no suporte e prejudicar a imobilização, porém a cinética de imobilização em termos de proteínas totais observada indica que a maioria das proteínas contaminantes presentes no sobrenadante não foram imobilizadas no suporte. Os parâmetros relacionados ao processo de imobilização encontram-se na Tabela 1.

Tabela 1 - Parâmetros de imobilização de xilanase recombinante de Bacillus subtilis (BsXA) em quitosana-glioxil (onde $A_{o f}=$ atividade oferecida na imobilização; $\mathrm{R}_{\mathrm{IU}}$ = rendimento de imobilização; $\mathrm{A}_{\mathrm{t}}=$ atividade teórica do derivado; $\mathrm{A}_{\mathrm{der}}=$ atividade medida do derivado; $\mathrm{AR}=$ atividade recuperada)

\begin{tabular}{cc}
\hline Parâmetros de Imobilização & Valores \\
\hline $\mathrm{A}_{\text {of }}\left(\mathrm{UI} / \mathrm{g}_{\mathrm{gel}}\right)$ & $180.1 \pm 7.6$ \\
$\mathrm{R}_{\mathrm{IU}}(\%)$ & $76.2 \pm 0.0$ \\
$\mathrm{~A}_{\mathrm{t}}\left(\mathrm{UI} / \mathrm{g}_{\mathrm{gel}}\right)$ & $137.2 \pm 5.8$ \\
$\mathrm{~A}_{\text {der }}(\mathrm{UI} / \mathrm{g})$ & $72.4 \pm 3.4$ \\
$\mathrm{AR}(\%)$ & $53.6 \pm 1.7$ \\
\hline
\end{tabular}

A atividade recuperada (AR) do processo foi de 53.6\%, mostrando uma provável inativação da 
xilanase na etapa de redução com borohidreto de sódio. Este comportamento também foi observado por outros autores, Mendes et al. (2011) estudando a imobilização de diferentes lipases em quitosana ativada com diferentes grupos reativos verificaram que, para todos os suportes testados, entre $11 \mathrm{e}$ $23 \%$ da atividade era perdida na etapa de redução. De acordo com os autores, a perda de atividade durante a redução com borohidreto de sódio está relacionada com uma possível redução das pontes dissulfeto da enzima.

A presença de proteína residual no sobrenadante, a qual manteve-se constante durante todo o processo, deve-se a presença de proteínas contaminantes no extrato enzimático que não imobilizam no suporte quitosana-glioxil devido à ausência ou ao reduzido número de grupos lisinas em sua superfície. Este comportamento indica a ocorrência de uma imobilização seletiva, na qual somente as enzimas que possuem um número significativo de resíduos de lisina são imobilizadas, que é o caso da enzima de interesse (BsXA).

A Figura 2 apresenta o perfil de inativação da xilanase livre e imobilizada a $56^{\circ} \mathrm{C}$ em tampão citrato $50 \mathrm{mM} \mathrm{pH}$ 5.5. Observa-se que a xilanase imobilizada foi significativamente mais estável que a solúvel, após 15 minutos de incubação o derivado conservou $92.6 \%$ de sua atividade inicial, enquanto a forma solúvel estava totalmente inativa. Os tempos de meia vida estimados são de 4.7 e 357.0 minutos para as enzimas livre e imobilizada, respectivamente. Desta maneira, a enzima imobilizada mostrou-se $75 x$ vezes mais estável que a enzima solúvel, este aumento na estabilidade se deve, provavelmente, às ligações multipontuais formada entre a enzima e o suporte.

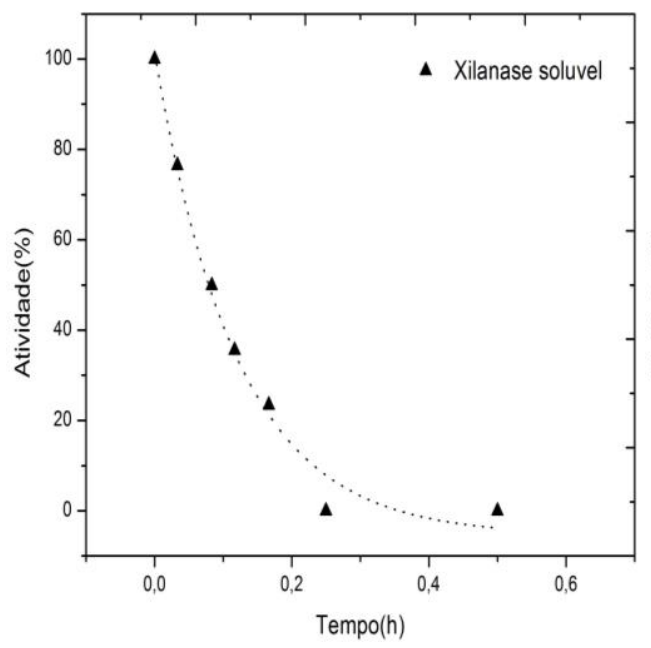

(A)

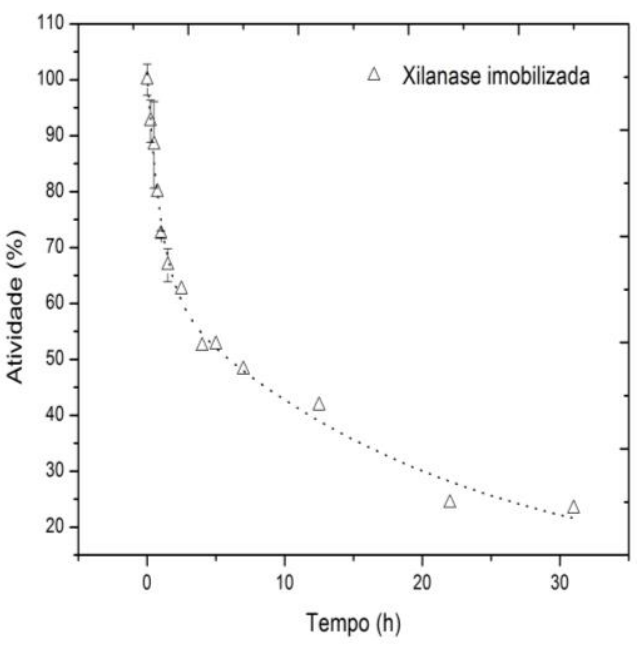

(B)

Figura 2 - Inativação térmica $\left(56^{\circ} \mathrm{C}\right.$ e pH 5.5) de xilanase recombinante de Bacillus subtilis (BsXA) solúvel (A) e imobilizada em quitosana glioxil (B).

A hidrólise da hemicelulose é geralmente realizada em temperaturas mais amenas que $56^{\circ} \mathrm{C}$, 


\section{9 a 22 de outubro de 2014 \\ Florianópolis/SC}

geralmente são utilizadas temperaturas entre $40-50^{\circ} \mathrm{C}$ (Carvalho et al., 2013), desta maneira, considerando que a estabilidade enzimática diminui com o aumento da temperatura, o derivado de xilanase de $B$. subtilis obtido será ainda mais estável nas condições de processo, ou seja, apresentará tempo de meia vida consideravelmente superior ao observado a $56^{\circ} \mathrm{C}$.

Desta maneira, apesar do rendimento e atividade recuperada observados, a técnica proposta é interessante uma vez que a quitosana é um suporte barato com diversas vantagens e de fácil obtenção e o processo de ativação com grupos glioxil proposto além de novo mostrou-se efetivo e aumentou a estabilidade do derivado, compensando assim o baixo rendimento de imobilização

\section{CONCLUSÃO}

Foi possível ativar o suporte de quitosana com grupos glioxil utilizando epicloridrina como reagente de partida, a epicloridrina permitiu também o entrecruzamento do gel de quitosana aumentando sua estabilidade operacional e evitando sua dissolução quando empregado em valores ácidos de pH. A técnica de imobilização de enzimas por ligação covalente multipontual em quitosanaglioxil se mostrou eficiente para a imobilização da xilanase recombinante de Bacillus subtilis (BsXA). O processo apresentou rendimento de imobilização de $76.2 \%$ e atividade recuperada de 53.6\%. A perda de atividade e rendimento de imobilização observados podem ser justificados considerando-se que a quitosana é um suporte de baixo custo e o derivado obtido é significativamente mais estável que a enzima solúvel (75x mais estável à pH 5.5 e $\left.56^{\circ} \mathrm{C}\right)$.

\section{AGRADECIMENTOS}

Os autores agradecem ao Conselho Nacional de Desenvolvimento Científico e Tecnológico (CNPq) pelo apoio financeiro.

\section{REFERÊNCIAS}

ARAGON, C.C.; SANTOS, A.F.; RUIZ-MATUTE, A.I.; CORZO, N. Continuous production of xylooligosaccharides in a packed bed reactor with immobilized-stabilized biocatalysts of xilanase from Aspergillus versicolor. J Mol Catal B-Enzim, v.98, p.8-14, 2013

BERNIER, R.; DESROCHERS, M.; JURASEK, L.; PAICE, M. Isolation and characterization of a xilanase from Bacillus subtilis. Appl Environ Microb, v.46, n.2, p.511-514, 1983

BRADFORD, M.M.; A rapid and sensitive method for the quantitation of microgram quantities of protein utilizing the principle of protein-dye binding. Anal. Biochem, v 72, p.248-254, 1976.

CARVALHO, A.F.A.; NETO, P.O.; SILVA, D.F.; PASTORE, G.M. Xylo-oligosaccharides from lignocellulosic materials: Chemical structure, health benefits and production by chemical and enzymatic hydrolysis. Food Res Int, v.51, 75-85, 2013.

FENGEL, D.; WENEGER, G. Wood - Chemistry Ultrastructure Reactions. Berlin: Walter de Gruyter, 1983.

GUISAN, J. Aldehyde-agarose gels as activated supports for immobilization-stabilization of enzymes. 
Enzyme Microb Tech, v. 10, p. 375-382, 1988).

KUMAR, M.N.V.R. A review of chitin and chitosan applications. React Funct Polym, v.46, p-1-27, 2000

LOPEZ, F.; MONTES, T.; FUENTES, M.; ALONSO, N.; GRAZU, V.; BETANCOR, L.; et al. Improved stabilization of chemically aminated enzymed via multipoint covalente attachment on glyoxyl supports. J Biotechnol, v.116, p.1-10, 2005

MANRICH, A. Produção de xilo-oligossacarídeos a partir de lignocelulósicos pré-tratados com xilanases imobilizadas e estabilizadas. Tese de doutorado, Universidade Federal de São Carlos, Fevereiro de 2012.

MENDES A.A; CASTRO, H.F.; RODRIGUES, D.S.; ADRIANO, W.S.; TARDIOLI, P.W.;et al. Multipoint covalent immobilization of lipase on chitosan hybrid hydrogels: influence of the polyelectrolyte complex type and chemical modification on the catalytic properties of the biocatalysts. J. Ind. Microbiol. Biotechnol. v.38, p.1055-1066, 2011.

MILLER, G.L. Use of Dinitrosalicylic Acid Reagent for Determination od Reducing Sugar. Anal. Chem., v.31, 426-428, 1959.

MOSIER, N.; WYMAN, C.; DALE, B.; ELANDER, R.; LEE, Y.Y.; HOLTZAPPLE, M.; LADISCH, M. Features of promising technologies for pretreatment of lignocellulosic biomass. Bioresource Technol., v.96, p.673-686, 2005.

MUSSATO, S.I.; DRAGONE, G.; GUIMARÃES, P.M.R.; SILVA, J.P.A.; et al.Technological trends, global market and challenges of bio-ethanol production. Biotechnol. Adv., v.28, p.817-830, 2010.

NIGAM, P.S.; SINGH, A. Production of liquid biofuels from renewable resources. Prog. Energ. Combust., v.37, p.52-68, 2011.

RODRIGUES, D.S.; MENDES, A.A.; ADRIANO, W.S.; GONÇALVES, L.R.B.; GIORDANO, R.L.C. Multipoint covalent immobilization of microbial lipase on chitosan and agarose activated by different methods. J Mol Catal B-Enzim, v.51, p.100-109, 2008

ROJAS, M.J.; KOPP, W.K.; NETO, A.B.; et al. Imobilização e estabilização de xilanase recombinante de Bacillus subtilis em glioxil-agarose. XIX Simpósio Nacional de Bioprocessos, X Simpósio de Hidrólise Enzimática de Biomassas, Fóz do Iguaçú, 2013.

SHELDON, R.A. Enzyme Immobilization: The quest for optimum performance. Adv. Synth. Catal., v.349, p.1289-1307, 2007

SILVA, C.R.; ZANGIROLAMI, T.C.; et al. Na innovative biocatalyst for production of ethanol from xylose in a continuous bioreactor. Enzyme Microb Tech, v.50, p.35-42, 2012. 